\title{
Gastrointestinal, nutritional, endocrine, and microbiota conditions in autism spectrum disorder
}

\author{
Nicolás Loyacono, M.D. ${ }^{a, b}$, María L. Sanz, B.S. in Nutrition ${ }^{b}$, María D. Gerbi, M.D. ${ }^{b, c}$,
} Luis M. Martínez, M.D. ${ }^{b}$, María L. Ferreira, Ph.D. in Chemistry, ${ }^{b}$ and Roberto Iermoli, M.D. ${ }^{a, b}$

a. Hospital de Clínicas José de San Martín (HCJSM), Buenos Aires, Argentina.

b. Autism Spectrum Disorder-

Comprehensive Approach Team (Equipo Trastorno del Espectro AutistaEnfoque Integrador, TEA-EI).

c. Specialist in Pediatrics, Day Hospital, Hospital Municipal Dr. Leónidas Lucero, Bahía Blanca, Argentina.

E-mail address:

Nicolás Loyacono, M.D. nicoloya@hotmail.com

Funding:

None.

Conflict of interest: María Luján Ferreira, Ph.D. in Chemistry, is the mother of a boy diagnosed with autism spectrum disorder in 2003; she was an ad honorem scientific advisor for Hospital de Clínicas José de San Martín as per Resolution 3070/2015 by the National Scientific and Technical Research Council (Consejo Nacional de Investigaciones Científicas y Técnicas, CONICET) from $6 / 1 / 2015$ to $6 / 30 / 2019$.

Received: 7-4-2019 Accepted: 12-17-2019

\section{ABSTRACT}

Gastrointestinal, nutritional, metabolic, endocrine, and microbiota medical problems in pediatric patients diagnosed with autism spectrum disorder (ASD) are some of the coexisting medical conditions in ASD diagnosis. Their prevalence reaches more than $91 \%$ for gastrointestinal problems, up to $89 \%$ for nutritional and metabolic disorders, more than $50 \%$ for thyroid dysfunction, and up to $100 \%$ for microbiota-related conditions.

There is an urgency for medical practice to be updated and to include the assessment, testing, diagnosis, and treatment of these coexisting medical conditions in ASD diagnosis in the pediatric, adolescent, and adult population. A strict management of such conditions results in positive changes in the quality of life and symptoms based on which ASD is diagnosed many times. It should be based on high-quality scientific evidence with an adequate medical care and control.

Keywords:autismspectrumdisorder, gastrointestinal disorders, nutrition, microbiota, endocrine system diseases.

http: / / dx.doi.org/10.5546/aap.2020.eng.e271

To cite:Loyacono N, Sanz ML, Gerbi MD, Martínez LM, et al. Gastrointestinal, nutritional, endocrine, and microbiota conditions in autism spectrum disorder. Arch Argent Pediatr 2020;118(3):e271-e277.

\section{INTRODUCTION}

Autism spectrum disorders (ASDs) are diagnosed based on behavior, communication, and reciprocal interaction alterations and limited interests. The United States Centers for Disease Control and Prevention (CDC) reported, in 2018, that 1 in every 59 children (both males and females) aged 8 years from 11 sites under CDC follow-up in 2014 had ASD. ${ }^{1}$

Now in 2019, we know that people with ASD have multiple coexisting medical conditions (CMCs). ${ }^{2}$ The genetic model characterizes ASD as a static encephalopathy with a genetic prenatal basis. Neurodiversity views ASD as a way of being, another form of inhabiting the world. This review falls within a new model that considers ASD as the name given to the set of symptoms of a chronic, dynamic, and systemic encephalopathy: the comprehensive approach (CA).

It proposes to analyze coexisting medical conditions to ASD diagnosis considering that their management should not be referred to as "ASD treatments." In addition, coexisting medical conditions to ASD diagnosis are classified as contributing to, causing or comorbidities of symptoms based on which individual ASD is diagnosed. The term coexisting encompasses all these roles. Until they are adequately managed, it will not be possible to establish whether there is a correlation or not between managed coexisting medical conditions in ASD diagnosis and the symptoms based on which ASD was diagnosed. This process is neither fast nor simple or direct. It requires a thorough analysis by the expert physician treating the patient, as well as ongoing training and updating and family involvement.

\section{METHODOLOGY}

Published reviews, key articles, and consensuses on gastrointestinal, nutritional, and endocrine conditions in ASD were reviewed. The search was done using Pubmed, Science Direct, and Medline. Priority was given to papers published in high impact international journals (2009May 2019 period). Some earlier publications were also quoted given their relevance. Search criteria included the following key words: 
autism or ASD and gastrointestinal, nutrition, microbiota, dysbiosis, endocrine, intestinal permeability or digestive enzymes.

\section{RESULTS}

Below we include an analysis of recent, specific bibliography about gastrointestinal, microbiota, nutritional, and endocrine conditions in ASD.

\section{Gastrointestinal conditions}

Six of Kanner's 11 patients had eating disorders or dietary alterations. ${ }^{3}$ For decades, gastrointestinal conditions were considered $a$ part of autism worldwide. In Argentina, when ASD is diagnosed, gastrointestinal conditions are not taken into account. Such attitude should be reviewed, as reported before. ${ }^{4}$

In 2019, there are multiple published articles confirming countless past and present parental reports of gastrointestinal conditions in ASD. These are often related to problem behaviors, altered sensory responses, sleep and behavioral dysregulation, depression, anxiety, aggression, and irritability..$^{5-11}$ Externalizing behaviors and internalizing symptoms associated with gastrointestinal conditions vary among the different age groups of children with ASD. ${ }^{12}$ A recent meta-analysis confirmed the strong association between gastrointestinal disorders and autism. ${ }^{13}$ They are significantly related to ASD in the adult population. ${ }^{14}$

Esophagitis, gastritis, duodenitis and colitis have been described in children with ASD for 20 years. ${ }^{15}$ In 1999, Horvath warned that reflux esophagitis and disaccharide malabsorption may contribute to problem behaviors in non-verbal patients with autism. Horvath $(2002)^{16}$ reported gastrointestinal conditions in $80.2 \%$ of children with ASD; while Parracho (2005), ${ }^{17}$ in $91.4 \%$. In Horvath's series, $76 \%$ of children with ASD had intestinal permeability and $85 \%$, hepatic sulfation alterations. ${ }^{16}$ Reflux esophagitis was found in $25 / 36$ patients $(69 \%)$; chronic gastritis, in 15/36 (41.7\%); and chronic duodenitis, in 25/36 (69 \%). ${ }^{16}$ Parracho et al. reported that $43 \%$ of patients with ASD had abnormal stools. ${ }^{17}$

Kang et al. found that $80 / 164$ patients with ASD $(49 \%)$ had at least one gastrointestinal condition. ${ }^{18}$ Up to $3276 / 6300$ patients with ASD $(52 \%)$ showed gastrointestinal conditions in the Autism Speaks Autism Treatment Network (US AS ATN). ${ }^{19}$ Schrieber et al., reported that $61 \%$ of children with ASD had gastrointestinal symptoms that correlated to affective and behavioral symptoms. ${ }^{8}$ Furuta et al. proposed an algorithm for the management of constipation in children with ASD. ${ }^{20}$ According to the results by Peters et al., clinicians had to assess constipation and diarrhea or related symptoms in children with ASD who had prominent rigid-compulsive symptoms ${ }^{11}$ Ferguson et al. reported that, out of 340 children and adolescents with ASD aged 2-18 years, $221(65 \%)$ had constipation. ${ }^{12}$

The management of coexisting medical conditions to ASD diagnosis has been heterogeneous, which is the result of clinical study designs. Those studies have not considered coexisting medical conditions in ASD diagnosis other than gastrointestinal problems, which may affect the course of treatment of a coexisting medical condition in ASD diagnosis. Thus, the impact of diet has been analyzed in multiple articles, but other aspects have not been assessed. Microbiota status, nutritional deficiencies, endocrine disorders, and immune and autoimmune conditions may be present and affect study outcomes. The lack of lab tests and individual differences in gastrointestinal symptom onset in ASD should be taken into consideration. Physicians also have major difficulties to diagnose these conditions (especially in non-verbal children or those with altered sensory integration).

The most important findings in ASD include increased intestinal permeability, ${ }^{21}$ diarrhea, constipation, gastroesophageal reflux (all grades), liver enzymes alterations, digestive enzymes deficiency and intestinal dysbiosis. The latter may include benign bacterial flora alterations and fungal, parasitic, and bacterial infections. ${ }^{5,6,22,23}$ Many times, these medical conditions coexist with mitochondrial, toxicological, immune, and autoimmune diseases. ${ }^{4}$

De Magistris et al., found intestinal permeability in $36.7 \%$ of patients with ASD compared to $4.8 \%$ of controls. Gastrointestinal conditions were present in $46.7 \%$ of children with autism: constipation (45.5\%), diarrhea $(34.1 \%)$, and others like alternating diarrhea/constipation, abdominal pain, etc. $(15.9 \%)$. It has been reported that children with ASD and gastrointestinal symptoms and colitis supported the presence of a type of inflammatory bowel disease. ${ }^{21}$ There is high-quality evidence indicating that children with more severe forms of ASD develop the most severe gastrointestinal symptoms. Gorrindo et al., confirmed that the presence of gastrointestinal 
dysfunction was not associated with different dietary habits or medication status. Parental reports of gastrointestinal dysfunction are highly consistent with the subsequent clinical diagnosis. ${ }^{23}$

A consensus study ${ }^{20}$ (like the two consensus studies published by Buie et al., in Pediatrics in 2010 ${ }^{22,25}$ recommended that health care providers should be warned of the fact that gastrointestinal symptoms in patients with ASD could be atypical and evident only as a change in behavior, which represents a significant challenge for both parents and physicians. This may include the onset of self-harm, irritability, aggression or strange movements and postures. Kang et al. mentioned that gastrointestinal dysfunction symptoms were associated with sleep disorders and food intolerance. $^{18}$

Unfortunately, gastrointestinal conditions (among other coexisting medical conditions in ASD diagnosis) are not part of the routine assessment of people diagnosed with ASD. This is a reflection of several factors. The variability in the reported prevalence of gastrointestinal disorders (in general, not considering the presence or absence of additional coexisting medical conditions to ASD diagnosis) is a problem. The controversy related to gastrointestinal symptoms and the causes of autism, and the limited verbal ability of many patients with ASD are others. It is worth taking into account that clinicians and pediatricians (and also pediatric neurologists and psychiatrists, for example) are unaware that behavioral manifestations in people with ASD are indicators of gastrointestinal and other medical conditions. In general, they are considered, autism manifestations. This reflects attitudes that are the result of the training received in the different implemented models (genetic, neurodiverse or psychoanalytic).

\section{Microbiota}

In 2019, Fattorusso et al., confirmed that dysbiosis has been widely demonstrated in ASD and underlined the role of probiotics. ${ }^{26}$ Sanctuary et al. (2018) confirmed that the combination of specific protein intakes, poor digestion, reduced intestinal barrier integrity, and an altered microbiota composition and function accounts for the phenotypic pattern of ASD. ${ }^{27}$ The relation between the immune and gastrointestinal systems has been described. ${ }^{28}$ There are reports of the presence of multiple concurrent conditions in different subgroups of people diagnosed with ASD and attention deficit hyperactivity disorder. ${ }^{29}$
Kushak et al., demonstrated that the frequency of lactase deficiency was $58 \%$ in children younger than 5 years and $65 \%$ in older patients with autism. ${ }^{30}$ However, there is no protocol for a clinical exploration in the pediatric population with ASD. Williams et al. (2011) showed that ileal transcripts encoding disaccharidases and hexose transporters were deficient in autism. Dysbiosis was revealed through a metagenomic analysis of gut bacteria. A reduction was observed in Bacteroidetes, whereas Betaproteobacteria and the Firmicutes to Bacteroidetes ratio increased. ${ }^{31}$

Tests done in patients with ASD have shown the presence of abnormal bacteria that were not present in controls. In healthy individuals, a translocation of bacterial species to portions of the gastrointestinal system that are not usually hosts of these bacteria has been observed. ${ }^{17,31-33}$ Desulfovibrio species were detected in patients diagnosed with ASD, but not in the controls. ${ }^{34}$ Parracho et al., ${ }^{17}$ reported that $34.5 \%$ of children with ASD and $33.3 \%$ of their siblings had received more than 6 antibiotic courses, usually for respiratory tract disorders or ear infections, compared to $0 \%$ in the control, unrelated group. In their group of patients with ASD $(80.2 \%$ with gastrointestinal conditions), this percentage reached $54.5 \%$. Niehus et al., found a higher antibiotic use in the 0-2 year-old period in 75 children with ASD who were then diagnosed with autism, compared to controls. ${ }^{35}$

Gut flora abnormalities in ASD have been confirmed. ${ }^{36-38}$ Wang et al., presented an updated review about markers in relation to bacterial flora alterations. ${ }^{38}$ Kesli et al., published evidence on Clostridia infection in autism. A statistically significant difference was observed in the autism group in terms of urinary excretion of a 3-(3-hydroxyphenyl)-3-hydroxypropionic acid (HPHPA), a Clostridia metabolite. ${ }^{39}$

Observed metabolic/biochemical changes confirmed gut microbiota abnormalities. ${ }^{40,41}$ Bacterial toxins were found in the blood and correlated to the severity of ASD symptoms. ${ }^{37,42}$ Endotoxemia would result from the higher presence of pathogenic bacteria, together with an increased intestinal permeability. A study reported $36.5 \%$ anti-Candida immunoglobulin G (IgG) in plasma; ${ }^{43}$ another study observed a high presence of Candida in the stool samples of $57.5 \%$ of children with ASD. ${ }^{44}$

Chronic inflammation and gastrointestinal tract infection are associated with an activated immune system and increased proinflammatory 
cytokine levels. This has a direct brain effect and impacts on behavior, including increased anxiety, motivation and socialization problems, avoidance of new situations, and adherence to routine, repetitive tasks. ${ }^{45-47}$

There is a new sub-area known as psychomicrobiotic. ${ }^{48}$ Pathogenic bacterial and fungal overgrowth (dysbiosis), abnormal fermentation, and the production of short-chain organic acids are very often found in ASD. Disaccharidase enzyme deficiencies, intestinal permeability, parasitic infections, carbohydrate or dietary protein allergies / intolerance/ sensitivity (e.g., gluten, casein, and other soy proteins) and other alterations are part of the coexisting medical conditions in ASD diagnosis and their effects. These effects are mediated by the hypothalamicpituitary-adrenal axis, the autonomic nervous system/vagus nerve system, and serotonin signaling, all reported as abnormal in autism. 49,50

Intestinal permeability (or leaky gut) in ASD, together with microbiota imbalance, has been analyzed by Sajdel-Sulkowska et al. ${ }^{51}$ It has also been related to mitochondrial dysfunction in ASD. ${ }^{52}$ This is accompanied by increased bloodbrain barrier permeability as a distinctive finding in ASD. ${ }^{53,54}$

\section{Nutritional conditions}

Neggers reported on the importance of maternal folic acid (vitamin B9) and vitamin D in the risk for autism. ${ }^{55}$ On the other side, vitamin $\mathrm{D}$ serum levels were measured in 50 autistic children (aged 5-12 years) and 30 controls. Deficient and insufficient vitamin D levels were found in $40 \%$ and $48 \%$, respectively. ${ }^{56}$ Trivedi et al., demonstrated how proline-rich glutenand casein-derived peptides modulated cysteine transport (key in glutathione synthesis) in gastrointestinal and neural epithelial cells. ${ }^{57}$ The management of food allergies, also considering diet, has been reported in recent bibliographic reviews, both for coexisting medical conditions in ASD diagnosis and attention deficit hyperactivity disorder. ${ }^{58}$

A case-control study with 40 children with ASD and 113 healthy children aged 6-10 years showed that $20 \%$ had a body mass index below the $5^{\text {th }}$ percentile for children with a typical development. ${ }^{59}$ In their review, Kawicka et al. (2013) proposed that diet therapy was not enough for the "treatment of autism." Nutritional management targeted one or several duly diagnosed coexisting medical conditions in
ASD, and its results may affect ASD symptoms or not. The authors demonstrated the need for supplementation in the case of confirmed deficiencies of omega-3 fatty acids, vitamins, minerals, and probiotics for gut flora alterations, combined with psychological and medical interventions. ${ }^{60}$

Ali et al. (2011) reported high homocysteine levels and low folate and vitamin B12 values in a total of 40 people with ASD. ${ }^{61}$ Hamza et al. (2013) published that $54 \%$ of 50 children with autism and $58 \%$ of their mothers had iodine deficiency. This deficiency correlated negatively with ASD severity. ${ }^{62}$ Three studies found low essential fatty acid levels, whereas a fourth study did not. ${ }^{63-66}$

Adams et al. (2011) demonstrated that 55 children with autism, compared to 44 controls, had significant deficiencies due to insufficient B-complex vitamins, among others. The authors observed increased oxidative stress, reduced energy transport, and altered sulfation and detoxification. ${ }^{67}$

Pagan et al., studied serotonin and melatonin blood levels in a group of 278 patients with ASD, 506 first-degree relatives, and 416 healthy controls. Among ASD patients, $40 \%$ (35-46 \%) had serotonin levels above the $95^{\text {th }}$ percentile and $51 \%(47-57 \%)$ had melatonin levels below the $5^{\text {th }}$ percentile, compared to the other groups. ${ }^{68}$

A 2013 review on nutritional status and food preferences in ASD $^{60}$ established that, besides obesity, patients with ASD have a risk for malnutrition due to an inadequate dietary energy intake and the problems caused by a poor intestinal nutrient absorption, in addition to indigestion. Any deviation from a normal nutritional status (overweight, obesity, emaciation) in patients with ASD should serve as a warning to promote dietary management.

\section{Endocrine conditions}

Tareen et al., found low T3 levels with oxidative stress and reduced D2 activity in ASD. ${ }^{69}$ However, neonatal thyroid hormone measurements were normal in 78 patients. ${ }^{70}$ Desoky et al., reported significantly higher thyroid-stimulating hormone (TSH) levels, a high CD5 expression, and reduced vitamin D levels in ASD.${ }^{71}$ Significantly lower total serum cholesterol, cortisol, and estradiol levels and higher free testosterone and dehydroepiandrostenedione levels have been reported in males with ASD. ${ }^{72}$ Steroid dysregulation may affect anxiety, sleep disorders, sensory deficits, and stereotypies. 
People with ASD have a higher prevalence of medical conditions, a mortality rate up to 9 times higher than the typical population, a greater health system use and higher costs. However, they experience multiple barriers to an adequate access to medical care in the USA..$^{73}$ In Argentina, the situation is similar. And, this must be reversed. The local bibliography includes algorithms for the assessment of coexisting medical conditions in ASD diagnosis. ${ }^{4}$ Adams et al., published, in 2018, a randomized, controlled, 12-month, single-blind clinical trial with a comprehensive nutritional and dietary intervention in 67 children and adults with ASD aged 3-58 years. The study reported an increased non-verbal intelligence quotient and communication, daily living skills, and social skills. Aberrant behaviors, sensory difficulties, and gastrointestinal and autism symptoms have been found to be reduced. ${ }^{74}$

ASD-associated genes may increase the susceptibility to develop extra-cerebral coexisting medical conditions in ASD diagnosis. Correlations between the immune system and different metabolic pathways have been described. ${ }^{2}$ The recent bibliography insists on assessing, diagnosing, and managing coexisting medical conditions in ASD diagnosis to promote health, progression, and quality of life in the setting of the necessary support for symptoms external to ASD. ${ }^{4,75,76}$ It is worth noting that the prevalence of nutritional conditions has been reported to be $46 \%-89 \%,{ }^{77}$ more than $50 \%$ for thyroid dysfunction, ${ }^{78}$ and up to $100 \%$ for microbiota alterations. $36,45,51,52$

Health care providers should consider gastrointestinal dysfunction (and other coexisting medical conditions in ASD diagnosis) in every patient with ASD, but specifically in those with strange movements or postures, sleep disorders, attention deficit, hyperactivity, food intolerance or selectivity, behaviors associated with food adverse reactions, and aggressive and selfharming behaviors.

\section{CONCLUSIONS}

In this article, we include part of the basic bibliography to be considered in the individual management of coexisting medical conditions in ASD diagnosis in the pediatric, adolescent, and adult population. It describes the importance of an adequate diagnosis and management of coexisting medical conditions in ASD diagnosis and the time necessary to provide a good quality of life for patients and their families, and underlines the need to carefully consider parents' contributions in relation to patients' medical history and team with the family. High-quality information, updated to 2019, should be provided in relation to coexisting medical conditions in ASD diagnosis, advanced approach models, and the relevance of family involvement in the management of coexisting medical conditions in ASD diagnosis.

\section{REFERENCES}

1. Baio J, Wiggins L, Christensen DL, Maenner MJ, et al. Prevalence of Autism Spectrum Disorder Among Children Aged 8 Years - Autism and Developmental Disabilities Monitoring Network, 11Sites, United States, 2014. MMWR Surveill Summ. 2018; 67(6):1-23.

2. Tye C, Runicles AK, Whitehouse AJO, Alvares GA. Characterizing the Interplay Between Autism Spectrum Disorder and Comorbid Medical Conditions: An Integrative Review. Front Psychiatry. 2019; 9:751.

3. Kanner L. Autistic disturbances of affective contact. Nervous Child. 1943; 2:217-50.

4. Loyacono N, Ferreira ML, Iermoli R. Humanismo en medicina. El rol crucial del pediatra en el trastorno del espectro autista. Arch Argent Pediatr. 2019; 117(3):195-7.

5. Holingue C, Newill C, Lee LC, Pasricha PJ, et al. Gastrointestinal symptoms in autism spectrum disorder: A review of the literature on ascertainment and prevalence. Autism Res. 2018; 11(1):24-36.

6. Chaidez V, Hansen RL, Hertz-Picciotto I. Gastrointestinal problems in children with autism, developmental delays or typical development. J Autism Dev Disord. 2014; 44(5): 1117-27.

7. Chandler S, Carcani-Rathwell I, Charman T, Pickles A, et al. Parent-reported gastro-intestinal symptoms in children with autism spectrum disorders. J Autism Dev Disord. 2013; 43(12):2737-47.

8. Mazefsky CA, Schreiber DR, Olino TM, Minshew NJ. The association between emotional and behavioral problems and gastrointestinal symptoms among children with highfunctioning autism. Autism. 2014; 18(5):493-501.

9. Coury DL, Ashwood P, Fasano A, Fuchs G, et al. Gastrointestinal conditions in children with autism spectrum disorder: developing a research agenda. Pediatrics. 2012; 130(Suppl 2):S160-8.

10. Mazurek MO, Vasa RA, Kalb LG, KanneSM, et al. Anxiety, sensory over-responsivity, and gastrointestinal problems in children with autism spectrum disorders. J Abnorm Child Psychol. 2013; 41(1):165-76.

11. Peters B, Williams KC, Gorrindo P, Rosenberg D, et al. Rigid-Compulsive Behaviors are Associated with Mixed Bowel Symptoms in Autism Spectrum Disorder. J Autism Dev Disord. 2014; 44(6):1425-32.

12. Ferguson BJ, Dovgan K, Takahashi N, Beversdorf DQ. The Relationship Among Gastrointestinal Symptoms, Problem Behaviors, and Internalizing Symptoms in Children and Adolescents With Autism Spectrum Disorder. Front Psychiatry. 2019; 10:194.

13. McElhanon BO, McCracken C, Karpen S, Sharp WG. Gastrointestinal Symptoms in Autism Spectrum Disorder: A Meta-analysis. Pediatrics. 2014; 133(5):872-83.

14. Croen LA, Zerbo O, Qian Y, Massolo ML, et al. The health status of adults on the autism spectrum. Autism. 2015; 19(7):814-23. 
15. Horvath K, Papadimitriou JC, Rabsztyn A, Drachenberg C, et al. Gastrointestinal abnormalities in children with autistic disorder. J Pediatr. 1999; 135(5):559-63.

16. HorvathK, PermanJA. Autistic disorderand gastrointestinal disease. Curr Opin Pediatr. 2002; 14(5):583-7.

17. Parracho HM, Bingham MO, Gibson GR, McCartney AL. Differences between the gut microflora of children with autistic spectrum disorders and that of healthy children. $J$ Med Microbiol. 2005; 54(Pt 10):987-91.

18. Kang V, Wagner GC, Ming X. Gastrointestinal dysfunction in children with autism spectrum disorders. Autism Res. 2014; 7(4):501-6.

19. Perrin J. Autism spectrum disorder and comorbid conditions. In: Interagency Autism Coordinating Committee. Bethesda, Maryland:July 9, 2013. [Accessed on: December $\left.26^{\text {th }}, 2019\right]$. Available at: https: / /iacc.hhs.gov / meetings / iacc-meetings/2013/full-committee-meeting/ july9/slides_james_perrin_070913b.pdf.

20. Furuta GT, Williams K, Kooros K, Kaul A, etal. Management of Constipation in Children and Adolescents With Autism Spectrum Disorders. Pediatrics. 2012; 130(Suppl2);S98-105.

21. De Magistris L, Familiari V, Pascotto A, Sapone A, et al. Alterations of the intestinal barrier in patients with autism spectrum disorders and in their first-degree relatives. $J$ Pediatr Gastroenterol Nutr. 2010; 51(4):418-24.

22. Buie T, Campbell DB, Fuchs GJ 3rd, Furuta GT, et al. Evaluation, diagnosis, and treatment of gastrointestinal disorders in individuals with ASDs: a consensus report. Pediatrics. 2010; 125(Suppl 1):S1-18.

23. Gorrindo P, Williams KC, Lee EB, Walker LS, et al. Gastrointestinal dysfunction in autism: parental report, clinical evaluation, and associated factors. Autism Res. 2012; 5(2):101-8.

24. Walker SJ, Fortunato J, Gonzalez LG, Krigsman A. Identification of unique gene expression profile in children with regressive autism spectrum disorder (ASD) and ileocolitis. PLoS One. 2013; 8(3):e58058.

25. Buie T, Fuchs GJ 3rd, Furuta GT, Kooros K, et al. Recommendations for evaluation and treatment of common gastrointestinal problems in children with ASDs. Pediatrics. 2010; 125(Suppl 1):S19-29.

26. Fattorusso A, Di Genova L, Dell'Isola GB, Mencaroni E, et al. Autism Spectrum Disorders and the Gut Microbiota. Nutrients. 2019; 11(3):E521.

27. Sanctuary MR, Kain JN, Angkustsiri K, German JB. Dietary Considerations in Autism Spectrum Disorders: The Potential Role of Protein Digestion and Microbial Putrefaction in the Gut-Brain Axis. Front Nutr. 2018; 5:40.

28. Rudzki L, Szulc A. "Immune Gate" of PsychopathologyThe Role of Gut Derived Immune Activation in Major Psychiatric Disorders. Front Psychiatry. 2018; 9:205.

29. Muskens JB, Velders FP, Staal WG. Medical comorbidities in children and adolescents with autism spectrum disorders and attention deficit hyperactivity disorders: a systematic review. Eur Child Adolesc Psychiatry. 2017; 26(9):1093-103.

30. Kushak RI, Lauwers GY, Winter HS, Buie TM. Intestinal disaccharidase activity in patients with autism: effect of age, gender, and intestinal inflammation. Autism. 2013; 15(3):285-94.

31. Williams BL, Hornig M, Buie T, Bauman ML, etal. Impaired carbohydrate digestion and transport and mucosal dysbiosis in the intestines of children with autism and gastrointestinal disturbances. PLoS One. 2011; 6(9):e24585.

32. De Angelis M, Piccolo M, Vannini L, Siragusa S, et al. Fecal microbiota and metabolome of children with autism and pervasive developmental disorder not otherwise specified. PLoS One. 2013; 8(10):e76993.

33. Ekiel A, Aptekorz M, Kazek B, Wiechula B, et al. Intestinal microflora of autistic children. Med Dosw Mikrobiol. 2010; 62(3):237-43.

34. Finegold SM, Dowd SE, Gontcharova V, Liu C, et al. Pyrosequencing study of fecal microflora of autistic and control children. Anaerobe. 2010; 16(4):444-53.

35. Niehus R, Lord C. Early medical history of children with autism spectrum disorders. J Dev Behav Pediatr. 2006; 27(2 Suppl):S120-7.

36. Cao X, Lin P, Jiang P, Li C. Characteristics of the gastrointestinal microbiome in children with autism spectrum disorder: a systematic review. Shanghai Arch Psychiatry. 2013; 25(6):342-53.

37. Hsiao EY. Gastrointestinal issues in autism spectrum disorder. Harv Rev Psychiatry. 2014; 22(2):104-11.

38. Wang L, Christophersen CT, Sorich MJ, Gerber JP, et al. Increased abundance of Sutterella spp. and Ruminococcus torques in feces of children with autism spectrum disorder. Mol Autism. 2013; 4(1):42.

39. Keşli R, Gökçen C, Buluğ U, Terzi Y. Investigation of the relation between anaerobic bacteria genus clostridium and late-onset autism etiology in children. J Immunoassay Immunochem. 2014; 35(1):101-9.

40. Ming X, Stein TP, Barnes V, Rhodes N, et al. Metabolic perturbance in autism spectrum disorders: A metabolomics study. J Proteome Res. 2012; 11(12):5856-62.

41. Yap IK, Angley M, Veselkov KA, Holmes E, et al. Urinary metabolic phenotyping differentiates children with autism from their unaffected siblings and age-matched controls. J Proteome Res. 2010; 9(6):2996-3004.

42. Emanuele E, Orsi P, Boso M, Broglia D, et al. Low-grade endotoxemia in patients with severe autism. Neurosci Lett. 2010; 471(3):162-5.

43. Hughes HK, Ashwood P. Anti-Candida albicans IgG Antibodies in Children With Autism Spectrum Disorders. Front Psychiatry. 2018; 9:627.

44. Iovene MR, Bombace F, Maresca R, Sapone A, et al. Intestinal Dysbiosis and Yeast Isolation in Stool of Subjects with Autism Spectrum Disorders. Mycopathologia. 2017; 182(34):349-63.

45. Cryan JF, Dinan TG. Mind-altering microorganisms: the impact of the gut microbiota on brain and behaviour. Nat Rev Neurosci. 2010; 13(10):701-12.

46. Goehler LE, Gaykema RP. Neural pathways mediating behavioral changes associated with immunological challenge. In: Siegel A, Zalcman S (eds.). The Neuroimmunological Basis of Behavior and Mental Disorders. New York: Springer; 2009.Pages 35-58.

47. Goehler LE, Gaykema R, Opitz N, Reddaway R, et al. Activation in vagal afferents and central autonomic pathways: Early responses to intestinal infection with Campylobacter jejuni. Brain Behav Immun. 2005; 19(4):334-44.

48. Fond G, Boukouaci W, Chevalier G, Regnault A, et al. The "psychomicrobiotic": Targeting microbiota in major psychiatric disorders: A systematic review. Pathol Biol (Paris). 2015; 63(1):35-42.

49. Diaz Heijtz R, Wang S, Anuar F, Qian Y, et al. Normal gut microbiota modulates brain development and behavior. Proc Natl Acad Sci U S A. 2011; 108(7):3047-52.

50. Foster JA, McVey Neufeld KA. Gut-brain axis: how the microbiome influences anxiety and depression. Trends Neurosci. 2013; 36(5):305-12.

51. Sajdel-Sulkowska EM, Zabielski R. Determinans of individual sensitivity of brain-gut axis and gut microbiome to enviromental toxins; intrinsic and extrinsic components. In: Gut Microbiome and Brain-Gut Axis in Autism Aberrant Development of Gut-Brain Communication and Reward Circuitry. Recent Advances in Autism Spectrum Disorders - 2013. [Accessed on: December 20 ${ }^{\text {th }}$, 2019]. 
Available at: https://www.intechopen.com/books/ recent-advances-in-autism-spectrum-disorders-volume-i/ gut-microbiome-and-brain-gut-axis-in-autism-aberrantdevelopment-of-gut-brain-communication-and-rewa.

52. Macfabe D. Autism: metabolism, mitochondria, and the microbiome. Glob Adv Health Med. 2013; 2(6):52-66.

53. Kealy J, Greene C, Campbell M. Blood-brain barrier regulation in psychiatric disorders. Neurosci Lett. 2018; 30:133664.

54. Fiorentino M, Sapone A, Senger S, Camhi SS, et al. Bloodbrain barrier and intestinal epithelial barrier alterations in autism spectrum disorders. Mol Autism. 2016; 7:49 AM.

55. Neggers YH. Increasing prevalence, changes in diagnostic criteria, and nutritional risk factors for autism spectrum disorders. ISRN Nutr. 2014; 2014:514026.

56. Mostafa GA, Al-Ayadhi LY. Reduced serum concentrations of 25-hydroxy vitamin $\mathrm{D}$ in children with autism: relation to autoimmunity. J Neuroinflammation. 2012; 9:201.

57. Trivedi MS, Shah JS, Al-Mughairy S, Hodgson NW, et al. Food-derived opioid peptides inhibit cysteine uptake with redox and epigenetic consequences. J Nutr Biochem. 2014; 25(10):1011-8.

58. De Theije CG, Bavelaar BM, Lopes da Silva S, Korte $\mathrm{SM}$, et al. Food allergy and food-based therapies in neurodevelopmental disorders. Pediatr Allergy Immunol. 2014; 25(3):218-26.

59. Bauset SM, Zazpe I, Sanchis AM, González AL, et al. Are there anthropometric differences between autistic and healthy children? J Child Neurol. 2013; 28(10):1226-32.

60. Kawicka A, Regulska-Ilow B. How nutritional status, diet and dietary supplements can affect autism. A review. Rocz Panstw Zakl Hig. 2013; 64(1):1-12.

61. Ali A, Waly MI, Al-Farsi YM, Essa MM, et al. Hyperhomocysteinemia among Omani autistic children: a case-control study. Acta Biochim Pol. 2011; 58(4):547-51.

62. Hamza RT, Hewedi DH, Sallam MT. Iodine deficiency in Egyptian autistic children and their mothers: relation to disease severity. Arch Med Res. 2013; 44(7):555-61.

63. Bell JG, MacKinlay EE, Dick JR, MacDonald DJ, et al. Essential fatty acids and phospholipase A2 in autistic spectrum disorders. Prostaglandins Leukot Essent Fatty Acids. 2004; 71(4):201-4.

64. Meguid NA, Atta HM, Gouda AS, Khalil RO. Role of polyunsaturated fatty acids in the management of Egyptian children with autism. Clin Biochem. 2008; 41(13):1044-8.

65. Vancassel S, Durand G, Barthelemy C, Lejeune B, et al. Plasma fatty acid levels in autistic children. Prostaglandins Leukot Essent Fatty Acids. 2001; 65(1):1-7.

66. Bu B, Ashwood P, Harvey D, King IB, et al. Fatty acid compositions of red blood cell phospholipids in children with autism. Prostaglandins Leukot Essent Fatty Acids. 2006; 74(4):215-21.

67. Adams JB, Audhya T, McDonough-Means S, Rubin RA, et al. Effect of a vitamin/mineral supplement on children and adults with autism. BMC Pediatr. 2011; 11:111.

68. Pagan C, Delorme R, Callebert J, Goubran-Botros H, et al. The serotonin-N-acetylserotonin-melatonin pathway as a biomarker for autism spectrum disorders. Transl Psychiatry. 2014; 4:e479.

69. Tareen RS, Kamboj MK. Role of endocrine factors in autistic spectrum disorders. Pediatr Clin North Am. 2012; 59(1):75-88.

70. Yau VM, Lutsky M, Yoshida CK, Lasley B, et al. Prenatal and Neonatal Thyroid Stimulating Hormone Levels and Autism Spectrum Disorders. J Autism Dev Disord. 2015; 45(3):719-30.

71. Desoky T, Hassan MH, Fayed HM, Sakhr HM. Biochemical assessments of thyroid profile, serum 25-hydroxycholecalciferol and cluster of differentiation 5 expression levels among children with autism. Neuropsychiatr Dis Treat. 2017; 13:2397-403.

72. Hassan MH, Desoky T, Sakhr HM, Gabra RH, et al. Possible Metabolic Alterations among Autistic Male Children: Clinical and Biochemical Approaches. J Mol Neurosci. 2019; 67(2):204-16.

73. Tregnago MK, Cheak-Zamora NC. Systematic review of disparities in health care for individuals with autism spectrum disorders in the United States. Res Autism Spectr Disord. 2012; 6(3):1023-31.

74. Adams JB, Audhya T, Geis E, Gehn E, et al. Comprehensive Nutritional and Dietary Intervention for Autism Spectrum Disorder-A Randomized, Controlled 12-Month Trial. Nutrients. 2018; 10(3):E369.

75. Frye RE, Rossignol DA. Identification and Treatment of Pathophysiological Comorbidities of Autism Spectrum Disorder to Achieve Optimal Outcomes. Clin Med Insights Pediatr. 2016; 10:43-56.

76. Loyacono N, Ferreira ML, Iermoli RH. Trastornos del Espectro Autista. Enfoque Integrador: del arte delo posible a la Investigación puesta en Práctica. Buenos Aires: Ediciones Globales; 2018.

77. Ledford JR, Gast DL. Feeding Problems in Children With Autism Spectrum Disorders A Review. Focus Autism Other Dev Disabl. 2006; 21(3):153-66..

78. Frye RE, Wynne R, Rose S, Slattery J, et al. Thyroid dysfunction in children with autism spectrum disorder is associated with folate receptor $\alpha$ autoimmune disorder. J Neuroendocrinol. 2017;29(3). doi: 10.1111/jne.12461. 